\title{
Malignant Gastrointestinal Tumours in South Western Nigeria: A Histopathologic Analysis of 713 Cases
}

\author{
Tumeurs Gastrointestinal Malfaisantes dans le Nigeria Sud-ouest : \\ Une Révision de Histopathologic de 713 Cas
}

\author{
F. B. Abdulkareem*†, F. A Faduyile ${ }^{\dagger}$ A. O. Daramola ${ }^{\dagger}$, O. Rotimi ${ }^{\ddagger}$, A. A F. Banjo ${ }^{\dagger}$, S. O. Elesha ${ }^{\dagger}$, \\ C. C.Anunobi ${ }^{\dagger}$ O. R. Akinde ${ }^{\dagger}$, E. K. Abudu ${ }^{\S}$
}

\begin{abstract}
BACKGROUND: Malignant tumours of the gastro-intestinal tract are not as rare as previous studies suggest. Recent studies have indicated increasing incidence.

OBJECTIVE: To document the pattern, age and sex distribution as well as histopathology characteristics of malignant tumours of the gastro-intestinal system in Lagos and Sagamu in Southwestern Nigeria.

METHODS: The paraffin embedded blocks and slides as well as pathology reports of malignant tumours of the gastrointestinal (GIT) organs collected from five laboratories (Morbid Anatomy Departments of the Lagos University Teaching Hospital and Olabisi Onabanjo University Teaching Hospital in Sagamu, Ogun State as well as the three private histolopathology laboratories in Lagos State) were reviewed. The clinical data such as the age, sex, and clinical summary were extracted from the records.

RESULTS: About $80 \%$ (578 cases) of all the 713 malignant GIT tumours were epithelial; sarcomas, carcinoid and non-Hodgkin's lymphoma being less common. The ages ranged from 4-96yrs (mean of 48.9years) with the peak in patients 60-69-year age group and M:F ratio of 1.35:1. Colorectal tumours topped the list with 402 cases $(56 \%)$, followed by liver $105(14.7 \%)$, stomach $85(12 \%)$ and omental metastases $67(9.4 \%)$. The oesophagus, pancreas, small intestine and gall bladder represented $18(2.5 \%)$, $16(2.2 \%), 12(1.7 \%)$, and eight $(1.1 \%)$ respectively. Colorectal cancers peaked in the 60-69 year age group, liver and stomach cancer occurred mostly between the 50-59 years age group. Over half of the colorectal adenocarcinomata were located in the ano-rectum with $93(23 \%)$ occurring in those below 40 years of age.
\end{abstract}

CONCLUSION: Colorectal cancer remains the commonest GIT tumour in the region. Molecular studies are imperative to identify the common subtypes of GIT tumours in order to ascertain their specific pathogenetic and prognostic features. WAJM 2009; 28(3) 173-176.

Key words: Malignant tumours; gastro-intestinal tumours; digestive system, colorectal cancer

\section{RÉSUMÉ}

CONTEXTE: les Tumeurs malignes du gastro-tube-digestifne sont pas aussi rares que les études précédentes suggèrent. Les études récentes ont indiqué l'incidence augmentante.

OBJECTIF: documenter le dessin, l'âge et la distribution sexuelle aussi bien que les caractéristiques histopathology de tumeurs malignes du système gastro-intestinal dans Lagos et de Sagamu dans le Nigeria Sud-ouest.

MÉTHODES: le pétrole a fixé des blocs et des glissements aussi bien que des rapports de pathologie de tumeurs malignes du gastrointestinal (le CONARD) les organes recueillis de cinq laboratoires (les Départements d'Anatomie Morbides de l'Hôpital d'Enseignement d'université Lagos et d'Olabisi Onabanjo l'Hôpital d'Enseignement d'université dans Sagamu, État d'Ogun aussi bien que les trois laboratoires histolopathology privés dans l'État Lagos) ont été reconsidérés. Les données cliniques telles que l'âge, le sexe et le résumé clinique ont été extraites des dossiers(archives).

RÉSULTATS: Environ $80 \%$ (578 cas) de toutes les 713 tumeurs de CONARD malfaisantes étaient épithéliaux; les sarcomes, carcinoid et le lymphoma de non-Hodgkin étant moins répandu. Les âges ont varié de 4-96yrs (moyen de 48.9 ans) avec le pic dans les patients 60 tranche d'âge de 69 années et rapport M:F de 1.35:1. Les tumeurs de Colorectal ont dépassé la liste avec 402 cas (56\%), suivis par le foie $105(14.7 \%)$, l'estomac 85 (12\%) et les métastases omental 67 (9.4 $\%)$. L'oesophagus, le pancréas, l'intestin grêle et la vésicule biliaire ont représenté $18(2.5 \%), 16(2.2 \%), 12(1.7 \%)$ et huit $(1.1 \%)$ respectivement. Les cancers de Colorectal ont culminé dans la tranche d'âge de 60-69 année, le foie et le cancer d'estomac se sont produits surtout entre la tranche d'âge 50-59yrs. La plus de moitié du colorectal adenocarcinomata a été localisée dans le l'ano-rectum avec 93 (23 $\%)$ se produisant dans ceux au-dessous de 40 ans d'âge.

CONCLUSION: le cancer de Colorectal reste la tumeur de CONARD la plus commune dans la région. Les études moléculaires sont impératives pour identifier les sous-types communs de tumeurs de CONARD pour vérifier leur pathogenetic spécifique et traits pronostiques. WAJM 2009; 28 (3) 173-175.

Mots clé: les Tumeurs malignes, les tumeurs gastro-intestinales, le système digestif, colorectal le cancer

\footnotetext{
*Departments of Morbid Anatomy, College of Medicine University of Lagos, Idi-Araba, P.M.B. 12003, Surulere, Lagos, Nigeria. Histopathology \& Molecular Pathology, University of Leeds Teaching Hospital, Leeds, UK. ${ }^{\ddagger}$ Morbid Anatomy, Olabisi Onabanjo University Teaching Hospital, Sagamu.

*Correspondence: Dr. Fatimah B. Abdulkareem, College of Medicine University of Lagos, Idi-Araba, P.M.B.12003, Surulere, Lagos, Nigeria. E-mail: biade64@yahoo.co.uk

Abbreviations: GIT, Gastrointestinal tract; GIST, Gastrointestinal stromal tumour; HCC, Hepatocellular carcinoma; NHL, Non-Hodkins lymphoma; SW, South West; WHO, World Health Organisation.
} 


\section{INTRODUCTION}

Gastrointestinal tumours constitute one of the major tumour burden to man. Studies from Africa showed lower incidence compared to other parts of the world. ${ }^{1-3}$ In an eight year review in Ibadan (South West Nigeria) between 1958-65, William \& Edington reported that cancers of the large bowel and anus accounted for $3 \%$ of all malignant tumours. ${ }^{3}$ Holcombe \& Babayo also reported the low incidence of colorectal and gastric carcinomas compared to other malignancies in North East Nigeria. ${ }^{4}$ In Benin, Okobia and Aligbe reported similar trend with gastrointestinal malignancies accounting for $12.9 \%$ of all malignant diseases. ${ }^{5}$ This is in contrast to the finding of Abdul Aziz et al in which GIT cancers represented $29.3 \%$ of the total cancer burden in Saudi Arabia. ${ }^{6}$

Colorectal carcinoma is the commonest malignancy of the gastrointestinal tract in Nigeria and it occurs more in the young and middle aged; adenocarcinoma being the predominant type..$^{7-9}$ In other studies, liver cancer is the most common type in West Africa. ${ }^{10}$ The familial polyposis syndromes as well as dietary factors particularly high calorie intake, low fibre diet, high intake of refined carbohydrate, high intake of cholesterol and low intake of protective micronutrients such as vitamins A, C and $\mathrm{E}$ as well as increased faecal transit time and inadequate physical exercise have been implicated as high risk factors. ${ }^{11}$

The incidence of oesophageal cancer in many African countries such as Ivory Coast, Mali and the Gambia are low while in other African countries such as South Africa, Uganda and Zimbabwe, the incidence rate has risen considerably, especially in the cities. ${ }^{12}$ Epidemiological studies have also identified smoking, alcohol consumption, diet poor in fresh fruits and vegetables, consumption of food contaminated by Fusarium verticilloides, and HPV infections as risk factors associated with the development of cancer of the oesophagus, in certain sub regions in Africa. ${ }^{12}$

Prevalence of gastric carcinoma is generally low but has a variable incidence in the black population of sub-Saharan Africa. H. pylori has been classified, by the International Agency for Research in
Cancer as a class I carcinogen for gastric cancer ${ }^{13}$. However, in a review of gastric cancer in Nigeria, it was reported that there is a high sero-prevalence of between $80-85 \%$ of $\mathrm{H}$. pylori infection among healthy individuals in the country. Even though there is low incidence of gastric cancer, the intestinal type of gastric cancer associated with H.pylori infection predominates. ${ }^{14}$

The present communication is aimed at documenting the prevalence as well as histopathological characteristics of the various types of malignant tumours of the gastrointestinal organs in Lagos and Sagamu, West Nigeria, Nigeria.

\section{MATERIALSANDMETHODS}

The materials for this study consisted of slides, paraffin embedded blocks and histology report forms of all the malignant tumours of the gastroenterological organs received between 1995 and 2006 at the Morbid Anatomy department of Lagos University Teaching Hospital between 2004-2006 in three private histopathology laboratories that are present in Lagos State, and from the Morbid Anatomy Department of Olabisi Onabanjo University Teaching Hospital. These five laboratories service the three teaching hospitals, all the general hospitals as well as private hospitals in Lagos and Ogun states including the neighbouring states.

The relevant slides were retrieved from the archives and where necessary, new ones were prepared from the paraffin blocks and stained with routine haematoxylin and eosin stain. Special stains such as Periodic Acid Schiff stain, Alcian blue stain were utilized where necessary to demonstrate the presence of neutral and acid mucin respectively. The trichome stain was used for liver tissue to demonstrate post-cirrhotic hepatocellular carcinoma.

The clinical information such as the age, sex, and clinical summary were extracted from the demographic data. The tumours were classified using the standard histological characteristics (according to the WHO classification system) and the data were then analyzed using Microsoft Excel and presented as tables and figures.

\section{RESULTS}

A total of seven hundred and thirteen cases with an age ranged 4-96 years with it peak at 60-69 years of age group and mean of 48.9 years were received. The male: female ratio was 1.35:1.

Colorectal tumours were the most common with 40, 2 (56\%), cases, followed by one hundred and five $(14.7 \%)$ liver cases and eighty six (12\%) stomach cases. Omental metastases accounted for sixty seven $(9.4 \%)$ cases. In the absence of immune histochemistry, the primary sites of omental tumour could not be determined but all of them were aden carcinomas. The oesophagus, pancreas, small intestine and gall bladder represented $2.5 \%, 2.2 \%, 1.7$ and $1.1 \%$ respectively (Figure 1).

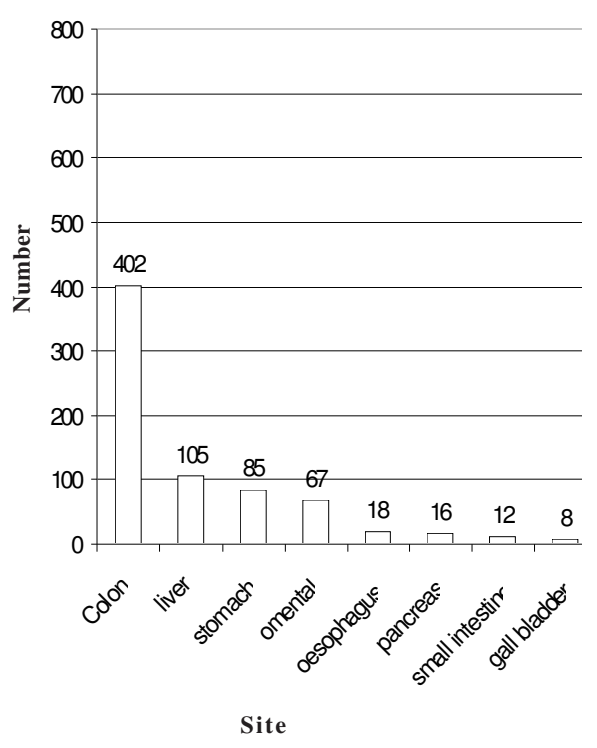

Figure 1: Site Distribution of Malignant Gastrointestinal Tumours

Malignant colorectal tumours (including the anus) showed two peaks. One of 40-49 years; another at 60-69 years while liver and stomach cancer occurred at age group 50-59 years. About $23 \%$ of colorectal tumours occurred below 40 years of age (Figure 2).

Three hundred and seventy nine (379 cases) of all the four hundred and two cases of malignant colorectal tumours were adenocarcinomas; the remaining being squamous cell carcinoma $(2.5 \%)$, sarcomas $(1.2 \%)$, non-Hodgkin's lymphoma $(1.0 \%)$ and characinoid tumour $(0.7 \%)$. The squamous cell carcinomas were located 

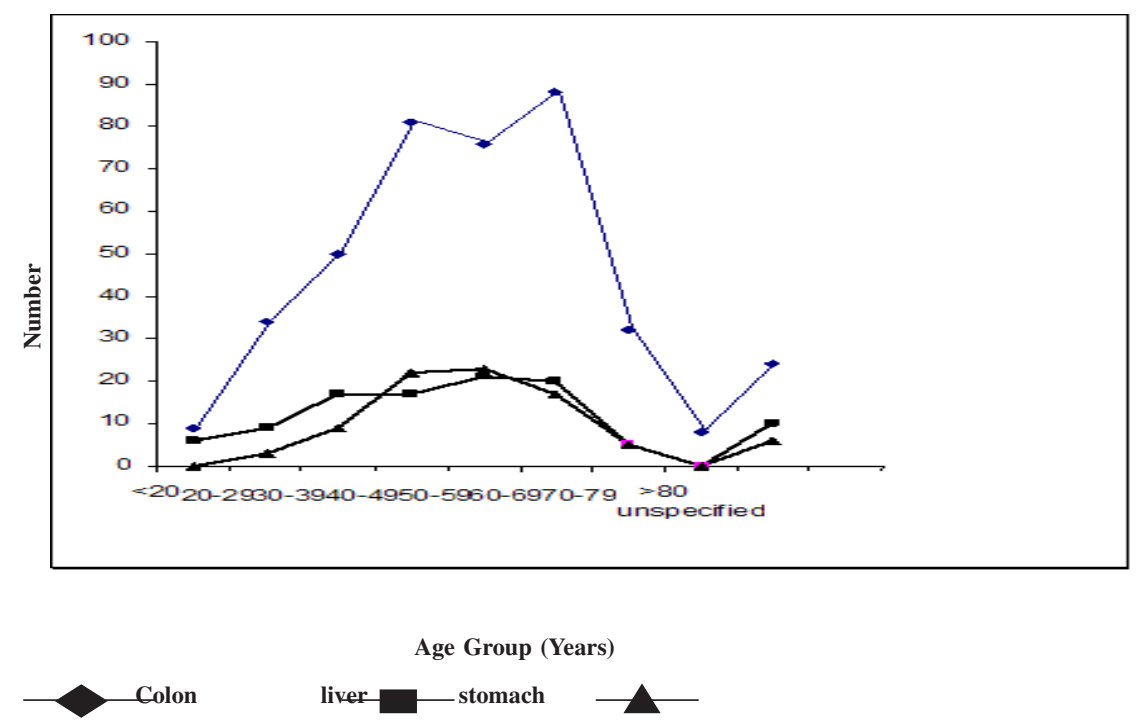

Figure 2: Distribution of Patients with Colon liver or Stomach by Age.

in the anus. Of the adenocarcinoma, $54 \%, 23.7 \%$ and $8.4 \%$ were well differentiated, moderately and poorly differentiated respectively; $10 \%$ were mutinous, signet ring type represented only $1.5 \%$.

Rectal carcinoma is the most commonly encountered (44\%), followed by the anus (10\%), the caesium $(8 \%)$, sigmoid $(7 \%)$, ascending $(7 \%)$, transverse $(4 \%)$ and descending colon (3\%) respectively. The site was not specified in $17 \%$ of cases.

Malignant tumours of the liver accounted for 105 cases (14.7\%) with a male to female ratio of 2: 1 and peak age between 50-59years. Hepatocellular carcinoma (HCC) accounted for $75 \%$ of all malignant liver tumours while metastatic carcinoma represented $17 \%$. Twenty-five percent of HCC were postcirrhotic. Other malignant tumours of the liver included cholangio-carcinoma, hepatoblastoma, non-Hodgkin's lymphoma and sarcoma (Figure 3).

Malignant gastric tumours accounted for eighty five (12\%) cases with male: female ratio of 1.8:1 and peak between 40-59 year age group. Majority $(92 \%)$ were adenocarcinomas, while mesenchymal tumours accounted for $5.8 \%$ of all gastric tumours. The other tumours encountered in the stomach were NHL and characinoid tumour. Eighty-six percent of the adenocarcinomas were of intestinal type while $10.5 \%$ were signet ring type; two cases of early gastric cancer were recorded.

Oesophageal cancers accounted for eighteen $(2.5 \%)$ cases with more than half of the cases occurring in the age group

50-69 years and almost equal sex incidence (M:F=1.1:1). Majority of the tumours were squamous cell carcinoma with twelve cases; more than half of which were poorly differentiated. One of them presented as a gastric mass by direct invasion to the stomach. The rest of them were adenocarcinoma and adeno-squamous carcinomas. There were sixteen cases of pan-creatic carcinoma representing $2.2 \%$ with a M:F ratio of $1.2: 1$ and mean age of 57.9 years. All of them were adenocarcinoma; seven of which are well differentiated.

Small intestinal tumours were uncommon accounting for only twelve cases $(1.7 \%)$ with $\mathrm{M}: \mathrm{F}$ ratio of $1.4: 1$ and mean age of 56.7 years. These included five cases of adenocarcinoma, four cases of malignant lymphoma, two cases of characinoid tumour and one case of metastatic choriocarcinoma. Gall bladder tumour accounted for eight cases (1.12\% of all GIT tumours) with M:F ratio of $0.3: 1$ and mean age of 63.3 years. All the gall bladder tumours were adeno-carcinoma with over half of them being well differentiated.

\section{DISCUSSION}

Of the total of seven hundred and thirteen cases of malignant GIT tumours reviewed, colorectal tumours were the most common with $56 \%$. This concurs with most previous studies which show that colorectal cancer is the most common GIT cancer with figures ranging between 53-67\%.5, 15, 16 In developed countries, it ranks among the three most common cancers. ${ }^{17}$ Earlier studies from Ibadan, Southern West Nigeria had showed lower incidence but after 2 decades, Iliyasu et al recorded $81 \%$ increase in colonic cancer from the same centre. ${ }^{7}$ The increase has been attributed to change in dietary content from fibre-rich to westernized low fibre diet as well other factors relating to increase in hospital attendance by the populace. The mean age of 49.9 years in the present series for colorectal cancer is comparable with 44.3 years, 44 years and 53 years recorded in Jos, Ibadan and Ife respectively and over $60 \%$ occurred in patients less than sixty years..$^{8-9,18}$ This contrasts the findings by Edino et al in Kano (Northern Nigeria) who reported that $72 \%$ occurred in patients below fifty years of age. ${ }^{19}$ About $23 \%$ of the colorectal tumours in the present series occurred below forty years of age, a figure which is lower than existing studies from other parts of Nigeria with figures ranging between $35-42 \% .^{7-8}$ In consonance with previous studies however, the predominant histological type in this series is adenocarcinoma with location in the distal colon and male sex preponderance. ${ }^{7-9,} 18$

Recent studies have shown that there are about five molecular subtypes of colorectal carcinoma having different pathogenetic pathways and these correlate with the morphological and prognostic features. ${ }^{21}$ It is no longer enough for pathologist to give microscopic diagnosis but also to provide other relevant prognostic information. There is a dearth of information on which of the types are common in Nigeria defined on the basis of the molecular features such as DNA micro satellite instability status and $\mathrm{CpG}$ island methylator phenotype which have variable prognostic significance. ${ }^{20}$ It is therefore imperative to know the specific subtype of colorectal carcinoma here in order to predict the pathogenetic and prognostic features and also to compare 
with the age and sex matched Caucasian tumours. Malignant tumours of the liver accounted for $14.7 \%$. Earlier studies had recorded malignant liver tumours as the most common cancer in Nigerian males. ${ }^{4}$ It was the most common GIT cance

accounting for $35.2 \%$ in the study by Atoba et al in Ibadan. ${ }^{10}$ Recently however, about $50 \%$ reduction in relative ratio frequency percent of liver cancer relative to other cancers was reported from the same centre over a period of two decades. ${ }^{21}$ The male predominance, age incidence in the six decade and its association with liver cirrhosis concur with previous studies. ${ }^{22}$

Malignant gastric tumours accounted for $12 \%$ of all the GIT tumours with male to female ratio of 1.8:1 and peak between 40-59year age group. The frequency of $12 \%$ is comparable to $13.3 \%$ recorded in Ibadan by Atoba et al but lower than $24.4 \%$ reported by Obafunwa in $\mathrm{Jos}^{10,15}$. The difference may be due to the fact that the latter study did not include other organs such as the liver, gall bladder, pancreas, etc. In comparison to other continents, gastric cancers are said to be relatively uncommon in Nigeria and other African countries compared with South East Asian and South American. ${ }^{14}$ The age incidence, male preponderance and histological characteristics recorded in this series are similar to reports in the literature. ${ }^{14}$ Helicobacter pylori has been strongly associated in the development of precancerous lesion of gastric carcinomas and despite high seroprevalence of between $80-85 \%$ in healthy individuals, detection rate of the organism in malignant tissue is quite low. ${ }^{14}$ The commonest type in this study which is the intestinal type is comparable to previous studies and has been shown to have better prognosis. It is associated with high level of proliferation and apoptosis as well as expression of some tumour suppressor genes such as FHIT, PTEN, p53 and MMP. ${ }^{23}$ Other types of malignancies in the stomach include lymphomas either as extra nodal primary non-Hodgkin's lymphoma or MALToma. Gastric mesenchymal tumours accounted for $5.8 \%$ in this series similar to report in the literature and majority have light microscopic features consistent with gastrointestinal stromal tumour (GIST). ${ }^{24}$

The frequency of oesophageal cancers recorded in this study is low (2.4\%). In many African based studies, oesophageal carcinoma ranges between $13.3 \%$ and $27.85 \%$ of all malignant gastrointestinal tumours seen. ${ }^{10,16,25}$

Small intestinal tumours and other malignant tumours of the GIT including pancreatic and gall bladder tumours are uncommon twelve $(1.7 \%)$, sixteen $(2.2 \%)$ and eight $(1.2 \%)$ respectively). Majority of pancreatic and gall bladder tumours are adenocarcinomas and are more common in males except gall bladder cancer that has a female preponderance.

Conclusion. Colorectal cancer remains the commonest GIT tumour. Liver cancer is second to this with significant percentage being postcirrhostic. Different molecular subtypes of colorectal carcinomas are known to have different morphological, pathogenetic and prognostic features. There is therefore the need to collaborate with centres in developed countries in this regard to determine specific molecular subtype of colorectal carcinoma in Nigerians and to compare with the age and sex matched Caucasian tumours. There is already an on going study in this regard with University of Leeds Teaching Hospital in the United Kingdom.

\section{ACKNOWLEDGEMENT}

We wish to acknowledge the contribution of the staff of both the Histopathology laboratory of the Lagos University teaching Hospital, Lagos Nigeria and research laboratory of Leeds General infirmary, Leeds, UK for their technical support. We also appreciate the cooperation of management and staff of The Specialist laboratory, HISTOLAB and SERAMOSES laboratories for giving us access to their records.

\section{REFERENCES}

1. Edington GM, Maclean CMU. A cancer rate survey in Ibadan, Western Nigeria, 1960-63.Br. J Cancer. 1965;19: 471-81.

2. Mulligan TO. The pattern of malignant disease in Ilesha, Western Nigeria. $B r J$ Cancer. 1970; 25: 1-10.

3. Williams AO, Edington GM. Malignant disease of the colon, rectum and anal canal in Ibadan, Western Nigeria. Dis Colon Rectum, 1967, 10: 301-308.

4. Holcombe C, Babayo U. The pattern of malignant disease in North East Nigeria. Trop \& Geogr Med. 1991; 43: 189-192.

5. Okobia MN, Aligbe JU. Pattern of malignant diseases at the University of Benin Teaching Hospital. Trop Doct. 2005; 35: 91-92.

6. Al Saigh AH, Allam MM, Zakaria M. Khan KA, Al Hawsawi ZM. Pattern of Cancer in Madina Al-Munawara Region. Ann Saudi Med 1995; 15: 350-3.

7. Iliyasu Y, Ladipo JK, Akang EE, Adebamowo CA, Ajao OG, Aghadiuno PU, et al. A twenty year review of malignant colorectal neoplasms at University College Hospital Ibadan, Nigeria. Dis Colon Rectum. 1996; 39: 536-540.

8. Sule AZ, Mandong BM, Iya D. Malignant colorectal tumours: a ten year review in Jos, Nigeria. West Afr J Med. 2001; 20: 251-255.

9. Elesha SO, Owonikoko TK. Colorectal neoplasms: a retrospective study. East Afr Med J. 1998; 75: 718-23.

10. Atoba MA, Olubuyide IO, Aghadiuno PO.
Gastrointestinal malignancies in a young tropical African population. Trop Doct. 1989: 135-136.

11. Kumar V, Abbas, AK, Nelson, F (Eds). Robins \& Cotran Pathologic basis of disease. Elsevier Saunders Inc, 7th ed. 2005: 864-865.

12. Walker AR, Adam F, Walker J, Walker BF. Cancer of the oesophagus in Africans in sub-Saharan Africa: any hopes for its control? Eur J Cancer Prev. 2002; 11: 413-418.

13. Mladenova I, Pellicano R. Infectious agents and gastric tumours. An increasing role for Epstein-Barr virus. Panminerva Med. 2003; 45: 183-188.

14. Oluwasola AO, Ogunbiyi JO. Gastric cancer: aetiological, clinicopathological and management patterns in Nigeria. Niger Med J 2003; 12: 177-186.

15. Obafunwa JO. Pattern of alimentary tract tumours in Plateau sate: a middle belt area of Nigeria. J Trop Med Hyg. 1990;93: 351-354.

16. Ohanaka CE, Ofoegbu RO. The pattern of surgical cancers in Nigeria: the Benin experience. Trop Doct. 2002, 32: 38-39.

17. Makinen MJ. Colorectal serrated adenocarcinoma. Histopathology. 2007, 50: 131-150.

18. Akinola DO, Arigbabu AO. Pattern and presentation of large bowel neoplasms in Nigerians. Cent Afr J Med. 1994; 40: 98-102.

19. Edino ST, Mohammed AZ, Ochicha O. Characteristics of colorectal carcinoma in kano, Nigeria: an analysis of 50cases. Niger J Med. 2005; 14: 161-166.

20. Jass JR. Classification of colorectal cancer based on correlation of clinical, morphological and molecular features. Histopathology 2007; 50: 113-130.

21. Otegbayo JA, Oluwasola OA, Akere A Ogunbiyi JO, Temporal and biological trends in livers in a University Hospital, South West Nigeria. Trop Doct, 2006, 36: 28-30.

22. Abdulkareem FB, Banjo AAF., Elesha, SO., Hepatic Neoplasms in Lagos, A 10 year histopathologic review of surgical biopsies. Niger Postgr Med J. 1999; 6: 126-129.

23. Zheng H, Takahashi H, Murai Y, Cui Z, Nomoto K, Miwa S. Pathobiological characteristics of intestinal and diffusetype gastric carcinoma in Japan: an immunostaining study on the tissue microarray. J Clin Pathol 2007; 60: 273-277.

24. Sugar I, Forgacs B, Istvan G, Bognar G, Sapy Z, Ondrejka P. Gastrointestinal stromal tumors (GIST). Hepatogastroenterology 2005; 52: 409-13.

25. Ahmed AA. The surgical management and outcome of oesophageal cancer in Addis Ababa. Ethiop Med J. 2000; 38: 147-152. 